
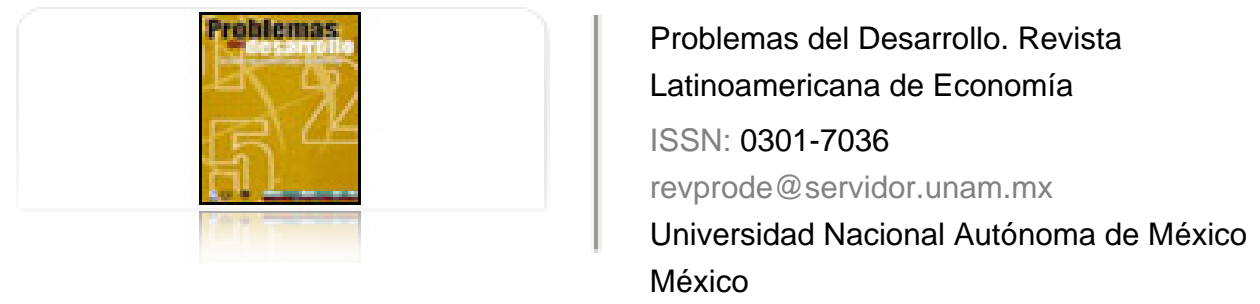

Solorza Luna, Marcia Luz

La economia cubana en la globalización mundial: ¿transición con rumbo?

Problemas del Desarrollo. Revista Latinoamericana de Economía, vol. 38, núm. 151, octubre-

diciembre, 2007, pp. 177-196

Universidad Nacional Autónoma de México

Distrito Federal, México

Disponible en: http://www.redalyc.org/articulo.oa?id=11820167009

Cómo citar el artículo

- Número completo

- Más información del artículo

Página de la revista en redalyc.org

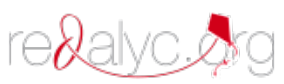

Sistema de Información Científica

Red de Revistas Científicas de América Latina, el Caribe, España y Portugal Proyecto académico sin fines de lucro, desarrollado bajo la iniciativa de acceso abierto 


\section{LA ECONOMÍA CUBANA EN LA GLOBALIZACIÓN MUNDIAL: ¿TRANSICIÓN CON RUMBO?}

\section{Marcia Luz Solorza Luna*}

Fecha de recepción: 8 de agosto de 2007. Fecha de aceptación: 1 de octubre de 2007.

\section{Resumen}

A partir de una revisión de la situación económica de Cuba este trabajo analiza algunos aspectos relevantes de la nueva inserción de la isla en la economía mundial en los años noventa e inicios del siglo XXI. Propone que el impacto de los factores externos en la última década del siglo XX agudizó los problemas económicos estructurales, y obligó a esa nación a tomar decisiones de política económica conduciéndola indudablemente en ese periodo a una transición económica e institucional. Luego examina cómo la transformación de las estructuras productivas e institucionales, incluidos los derechos de propiedad, se ha dado de forma lenta con fuertes ineficiencias, vaivenes políticos, con considerables costos sociales y altas tasas de crecimiento del Producto Interno Bruto (PIB) en condiciones externas desfavorables por el embargo estadounidense. Por último, concluye que Cuba es sin duda una economía en transición con grandes ambigüedades en el rumbo que habrá de seguir.

Palabras clave: transición, economía, reestructuración, Estado, financiamiento, crecimiento, inversión, reorientación.

* Profesora de la Facultad de Economía y en la División de Estudios de Posgrado de la UnAM. Correo electrónico: mlsolorza@yahoo.com.mx. 
Abstract

Beginning with a review of Cuba's economic situation, this study analyzes some aspects relevant to the Island's new insertion into the world economy in the 1990s and at the beginning of the 21st century. It proposes that the impact of external factors during the last decade of the 20th century sharpened its structural economic problems, obliging the country to take decisions on economic policy that led inevitably to an economic and institutional transition during that period. It then examines how the transformation of productive and institutional structures gradually occurred, including property rights, with severe inefficiencies, political fluctuations, and with considerable social costs and high Gross Domestic Product (GDP) growth rates in unfavorable external conditions due to the U.S. embargo. Finally, it concludes that Cuba is undoubtedly an economy in transition with large ambiguities regarding the route it will have to follow.

Key words: transition, economy, restructuring, State, financing, growth, investment, reorientation.

\section{Résumé}

À partir d'une révision de la situation économique de Cuba, ce travail analyse certains aspects importants de la nouvelle insertion de l'île dans l'économie mondiale depuis les années 90 et le début du XXIème siècle. Il est avancé que l'impact des facteurs externes a accru les problèmes économiques structuraux de cette nation dans la dernière décennie du XXème siècle, l'obligeant à prendre des décisions de politique économique qui l'ont manifestement conduite durant cette période à une transition économique et institutionnelle. Il est ensuite examiné comment la transformation des structures productives et institutionnelles, y compris les droits de propriété, s'est produite lentement avec une considérable inefficacité, des vicissitudes politiques, des coûts sociaux importants et de forts taux de croissance du produit intérieur brut (PIB) dans des conditions externes défavorables du fait de l'embargo des États-Unis. Enfin, il est conclu que l'économie de Cuba se trouve dans une phase de transition qui laisse de grandes incertitudes quant à l'orientation qu'elle devra suivre.

Mots clés: transition, économie, restructuration, État, financement, croissance, investissement, réorientation.

\section{Resumo}

A partir de uma revisão da situação econômica de Cuba este trabalho analisa alguns aspectos relevantes da nova inserção da ilha na economia mundial nos anos noventa e inícios do século XXI. Propõe que o impacto dos fatores externos na última década do século XX aguçou os problemas econômicos estruturais, e obrigou essa nação a tomar decisões de política econômica conduzindo-a indubitavelmente nesse período a uma transição econômica e institucional. A seguir examina como a transformação das estruturas produtivas e institucionais, incluindo os direitos de propriedade, aconteceu de forma lenta com fortes ineficiências, vaivens políticos, com consideráveis custos sociais e altas taxas de crescimento do Produto Interno Bruto (PIB) em condições externas desfavoráveis pelo embargo norte-americano. Por último, conclui que Cuba é sem dúvida uma economia em transição com grandes ambigüidades no rumo que haverá de seguir.

Palavras chave: transição, economia, reestruturação, Estado, financiamento, crescimento, investimento, reorientação. 


\section{Introducción}

a fusión de los mercados a escala mundial, desplegada desde hace dos o tres décadas, ocasionó cambios sustanciales en el ámbito económico de la mayoría de los países. La economía cubana se mantuvo al margen del proceso de globalización mundial en la materia hasta finales de los años ochenta. Sin embargo, la terminación de la Guerra Fría y la disolución del Consejo de Ayuda Mutua Económica (CAME) trastocaron el modelo económico de Cuba al romperse definitivamente las relaciones preferenciales sostenidas en ese rubro con la desaparecida URSS, mismas que contribuyeron a atenuar la presencia del bloqueo económico estadounidense.

El objetivo central de este trabajo es destacar los aspectos económicos relevantes de la nueva inserción de Cuba a la economía mundial en los años noventa y en el periodo 2000-2006.

En los años noventa el impacto de factores externos agudizó los problemas económicos estructurales, y obligó a Cuba a tomar decisiones de política económica que indudablemente la han conducido a una profunda transición económica e institucional. De 1990 a 2006 la transformación de las estructuras productivas e institucionales, incluidos los derechos de propiedad como elementos básicos del mercado (Coase, Ronald, 1960:144 y Coase, Ronald, 1992:714), se ha dado lentamente con fuertes ineficiencias y vaivenes políticos, con considerables costos sociales al deteriorarse las condiciones de vida de la población, y el paso de una crisis a una recuperación económica expresados en el comportamiento de las tasas de crecimiento del PIB que han oscilado entre -14.9 en 1993 y 12.5 para 2006, en situación externa desfavorable por el embargo estadounidense.

Ahora, Cuba es un complejo compuesto por la sociedad en transición, resultante del periodo transcurrido hasta 1990, más la gran tensión de la primera mitad de la década entre la crisis, la afirmación del régimen y la resistencia popular, más las transformaciones y permanencias del país desde finales de los años ochenta hasta 2007 (Martínez Heredia, 2004:104). Un complejo, porque no se reduce a una sucesión temporal, es una realidad específica que se resiste y avanza con matices propios hacia un rumbo económico similar al seguido por China 30 años atrás. Prioriza el perfeccionamiento del régimen de competencia sin alterar sustancialmente la propiedad 
pública (Stiglitz, Joseph, 1999:9-15) y el aparato estatal, hipótesis que demostraremos estadísticamente a lo largo de este trabajo.

\section{Aspectos generales}

En el periodo 1959-1989, Cuba — alejada de los mecanismos de comercialización y de las fases de crecimiento, depresión y recuperación vividas por los países capitalistas- logró establecer un "pacto social", una relación muy estrecha entre el poder estatal y el conjunto de la población, y un consenso alrededor de un proyecto nacional que hasta la fecha son la base del poder político y de su legitimidad. Igualmente, garantizó a su población el pleno empleo, el acceso a la educación y capacitación técnica; instituyó el derecho a la salud como parte de las políticas sociales de corte universal (para todos) siguiendo en este sentido el paradigma del Estado del Bienestar; invirtió en recursos para el desarrollo, especialmente en infraestructura, y en la mecanización de las labores agrícolas conforme a los planes de interés nacional, y al mismo tiempo mantuvo colaboración y capacidad negociadora con diversos países del mundo como Brasil, España, Argentina, Ecuador, México, Uruguay, Canadá y Vietnam, con los que la relación económica se ha replanteado en los últimos años en favor de Venezuela y China.

La generalización de alcances positivos en la construcción social de Cuba (la unidad, la disciplina y la cultura) y los esfuerzos estratégicos desempeñados en mejorar la posición industrializadora no fueron suficientes para superar la vieja estructura primario-exportadora del siglo XIX basada en la producción y exportación de azúcar, tabaco, níquel y productos pesqueros.

En la década de los noventa la situación política y económica de Cuba se transformó y dio lugar a un "periodo especial" con una crisis caracterizada por una severa contracción en el PIB (32\% entre 1989 y 1993), la caída de sus exportaciones (20.8\% en 1998), el aumento en la desocupación de fuerza de trabajo (7.9\% en 1995) e instalaciones productivas, el desabasto de alimentos y energía, la escalada de precios y la falta de divisas (Comisión Económica para América Latina y el Caribe, CEPAL, 2000: Anexo Estadístico). En tales circunstancias, la economía inició un proceso de descentralización basado cada vez más en las cotizaciones internacionales y el crecimiento del mercado. Por tanto, aun cuando la forma de organización social y las expresiones políticas no se vieron alteradas, la capacidad de acción estatal se vio reducida y se tornó necesario replantear las políticas públicas adaptándolas a la ascendente autonomía de la sociedad civil y a las transformaciones de las instituciones jurídicas y económicas (Aoki, Masahiko, 1995:330-353, y Sachs y Woo, 1994:49-76). 
El Estado cubano en los años noventa, a fin de contar con fuentes de financiamiento, modificó gradualmente el régimen de propiedad empresarial, permitió y fomentó la inversión extranjera directa, la formación de empresas privadas, y el desarrollo del sector exportador mediante la especialización y políticas adaptativas, al aplicar medidas de "planeación estratégica" para suavizar el aterrizaje a un modo de producción

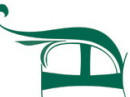
dominado por la competencia, la eficiencia, y la adaptación flexible a los mercados. A la par de esta radical medida de reorientación económica, Cuba siguió siendo el país con mayor porcentaje de tierra estatal del mundo; en 1993 se entregó en usufructo gratuito la mayor parte de las granjas estatales a sus colectivos de trabajadores para formar cooperativas, y para finales de 2005 el Estado era propietario de $58.2 \%$ de la superficie agrícola y de $85 \%$ del suelo no agrícola.

Así, Cuba ha buscado elevar su producción sin dilapidar recursos y aprovechar adecuadamente la ventaja competitiva de contar con fuerza de trabajo calificada capaz de asimilar nuevas tecnologías en poco tiempo. En 2000-2005 se da una disminución relativa de las personas con educación primaria como grado mayor de estudios al pasar de 16\% (745.8) a 10\% (514.7), y aumenta de manera significativa el número de trabajadores con un nivel educativo medio superior (entre los que se encuentra gran número de técnicos) y superior en el total de la población económicamente activa que, como puede observarse en cuadro 1, constituyen $45.6 \%(2,195.7)$ y $13 \%$ (662.1), respectivamente en 2005 .

Cuadro 1

Nivel Educativo de la Población Económicamente Activa (Miles de trabajadores)

\begin{tabular}{lrrrrrr}
\hline & \multicolumn{1}{c}{2000} & \multicolumn{1}{c}{2001} & \multicolumn{1}{c}{2002} & \multicolumn{1}{c}{2003} & \multicolumn{1}{c}{2004} & \multicolumn{1}{c}{2005} \\
\hline Total & $4,631.5$ & $4,696.7$ & $4,714.3$ & $4,716.6$ & $4,729.4$ & $4,816.4$ \\
Primario & 745.8 & 704.6 & 670.0 & 598.4 & 567.5 & 514.7 \\
Secundario & $1,416.5$ & $1,423.6$ & $1,435.5$ & $1,425.60$ & $1,409.5$ & $1,443.9$ \\
Med. Super. & $1,867.8$ & $1,938.2$ & $1,975.6$ & $2,032.40$ & $2,085.3$ & $2,195.7$ \\
Superior* & 601.4 & 630.3 & 633.2 & 660.2 & 667.1 & 662.1 \\
\hline
\end{tabular}

Fuente: Oficina Nacional de Estadísticas (ONE), Anuario Estadístico 2005 , Edición 2006, Cuba.

*En 2005 del total 70,594 son médicos, 89,462 enfermeras y 94,286 técnicos en salud.

Esta reestructuración económica, las exigencias organizacionales de las nuevas modalidades de propiedad (individual, cooperativa, estatal) y productivas, y el acelerado envejecimiento de la población (en la actualidad $16.2 \%$ de la población tiene 60 años o más) demandaron reformas fiscales, entrada de divisas que compensaran los desequilibrios financieros externos del país y colaboraran en su repunte económico — de ahí la apertura a la inversión extranjera directa-, y la conformación de un sistema bancario y financiero. 


\section{Reforma fiscal}

El proceso de reforma fiscal inició en 1994 con la promulgación de la Ley del Sistema Tributario (Presidencia del Consejo de Estado de la República de Cuba, 1994: Decreto de Ley Núm.73). Las empresas privadas fueron gravadas con un impuesto directo de 35\%, y las compañías estatales rentables se incorporaron de manera paulatina a este nuevo régimen. Las personas físicas ocupadas en las empresas privadas cumplen con el pago de impuesto progresivo como se hace en otros países de América Latina (Presidencia del Consejo de Estado de la República de Cuba, 1999: Decreto de Ley Núm. 192).

Respecto a los impuestos indirectos se ha avanzado de forma pausada en reemplazar el impuesto a la circulación de bienes por un gravamen a las ventas, práctica común en los países latinoamericanos con modelo económico neoliberal vigente.

El resultado de la reforma fiscal arroja que a partir del 2000 el sector privado de la economía tiene una contribución cercana a 15\% de los ingresos totales del Estado.

\section{Reformas al sistema bancario y financiero}

En 1997 comienza un proceso de reforma bancaria tratando de modernizar al sector y adecuarlo para subsanar la falta de financiamiento al sector productivo y generar competencia interbancaria. Se separaron las tareas propias de la banca central de las correspondientes a la banca comercial. Se creó un nuevo Banco Central de Cuba (BCC), autoridad rectora, reguladora y supervisora de las instituciones bancarias y financieras, con la responsabilidad de la emisión monetaria, de la estabilidad monetaria y servir de prestamista en última instancia (Presidencia del Consejo de Estado de la República de Cuba, 1997: Decreto de Ley Núm. 172). El antiguo Banco Nacional de Cuba (BNC) se convirtió en un banco comercial que transfiere su "estructura nacional" al Banco de Crédito y Comercio para realizar operaciones de banca universal en todo el territorio cubano. El Banco Popular de Ahorro (BPA), que se dedicaba a recibir ahorro y conceder créditos a las familias, se transformó en banca universal. A la par surgieron instituciones financieras especializadas como las aseguradoras, y diferentes bancos extranjeros abrieron agencias de representación (Presidencia del Consejo de Estado de la República de Cuba, 1997: Decreto de Ley Núm. 173).

Con estas medidas se abrió una nueva etapa para el sector financiero, donde la creciente participación empresarial en la vida económica de Cuba requería de créditos, de instrumentos propios del mercado de capitales y un control de las tasas 
de interés, del tipo de cambio y de la tasa de inflación (Banco Central de Cuba, 1998:15-16).

\section{Inversión extranjera directa}

Desde inicios de los años ochenta se dio la primera manifestación de apertura económica en Cuba, al aprobar el gobierno el Decreto-Ley Núm. 50, con lo que se permite la entrada de inversión extranjera directa a fin de elevar las exportaciones y alentar la introducción de tecnología moderna a ramas seleccionadas de la economía nacional (Presidencia del Consejo de Estado de la República de Cuba, 1982: Decreto de Ley Núm. 50), pero no fue sino hasta inicios de los años noventa que los flujos de inversión extranjera hacia Cuba comenzaron a crecer como respuesta a su nueva situación económica. Como puede apreciarse en la gráfica 1, en 1994 la inversión extranjera directa en Cuba alcanzó el monto máximo de 563.4 millones de pesos convertibles, y descendió abruptamente en 1995 con la promulgación de la Ley 77 (Presidencia del Consejo de Estado de la República de Cuba, 1995: Decreto de Ley Núm. 77) en la que se estableció la admisión selectiva y restrictiva de inversiones extranjeras en sectores económicos como: industria básica (energía, minería y cemento), turismo, construcción, industria ligera y agricultura, y quedó estrictamente prohibida en los sectores de salud, educación, y la industria para la defensa nacional. En la gráfica 1 las cifras nos muestran un periodo (1996-2001) de comportamiento errático de la inversión extranjera directa, mismo que no ha cumplido con el objetivo de compensar

Gráfica 1

Inversión Extranjera Directa (Millones de pesos)

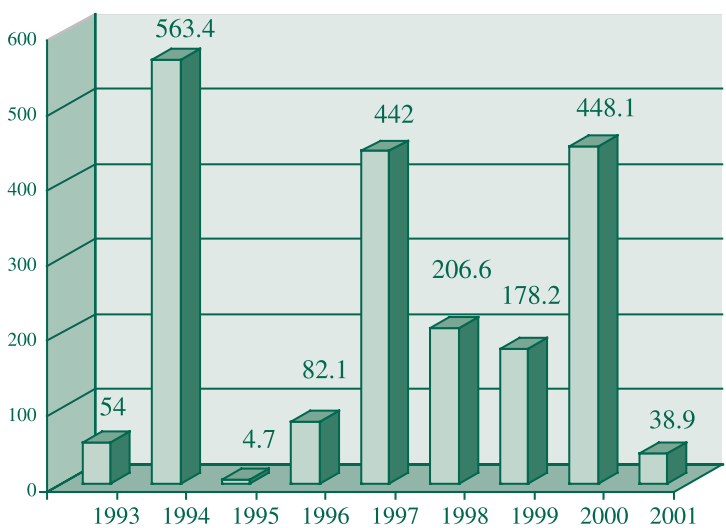

Fuentes: Oficina Nacional de Estadísticas, Anuarios Estadísticos de Cuba 1997 y 2001, La Habana, 1998 y 2002.

Panorama Económico y Social de Cuba, 2006, La Habana, 2007. 
el saldo negativo crónico de la cuenta corriente de la balanza de pagos. Las cifras de los montos de inversión extranjera directa para años posteriores a 2001 y por actividad económica no están disponibles en las publicaciones de la oficina Nacional de Estadísticas (ONE) de Cuba.

La participación de la inversión extranjera en la economía cubana, que acumuló dos mil 18 millones de pesos convertibles entre 1993 y 2001, a la fecha no ha repuntado porque en raras ocasiones se le autoriza más de $51 \%$ de la propiedad empresarial; tampoco se permite al público o a las empresas inversiones en la distribución comercial y en algunos servicios. Además la Ley de Inversiones Extranjeras fue complementada en 1996 con el Decreto de Ley 165 sobre Zonas Francas que exige que 75\% de las ventas sean exportaciones. Vista su escasa viabilidad, las zonas francas han cerrado de manera paulatina durante 2004 y 2005 para reorientarse hacia parques industriales y comerciales.

En el periodo 2001-2006 el número de empresas mixtas activas disminuyó de forma considerable; a principios de 2004 eran 313, pero cesaron actividades 275 compañías de las 588 creadas hasta 2003. En los últimos tres años el número y monto de las inversiones se han ralentizado debido a las dificultades operativas y al haberse revertido el proceso de apertura de la economía, lo que ha planteado interrogantes respecto al rumbo de la política económica. Durante 2004 sólo se crearon siete nuevas empresas mixtas con firmas canadienses, chinas y venezolanas, y se cancelaron algunas compañías inactivas y activas. En 2005 continuó el cierre de empresas mixtas y asociaciones internacionales con 60 unidades.

En 2006 las autoridades cubanas optaron por aplicar una política de racionalización y selección extrema de inversionistas extranjeros para tratar de mantener sólo a los de mayor tamaño que le ofrecen al país presencia en los mercados exteriores y un buen resultado financiero (dividendos, impuestos, salarios), o aquellos que ofrezcan bienes y servicios de especial interés. Ello ha llevado a una recomposición en los proyectos de inversión en Cuba hacia la industria básica (energía, minería y cemento), turismo, construcción, industria ligera y agricultura de acuerdo con los proyectos estatales y el país de origen de donde proviene el monto de inversión. España, Cana-

dá, Italia, Francia, Reino Unido, México y Holanda han perdido presencia, mientras Venezuela y China se han colocado como los principales socios de Cuba.

\section{Turismo}

El turismo, eje dinámico de la economía y de la inserción cubana al mercado mundial, en la década de los noventa llegó a aportar ingresos acumulados por nueve mil 
176.4 millones de pesos convertibles que significaron 55\% del total de ingresos por exportaciones de bienes y servicios; en los primeros tres años del siglo XXI mostró un estancamiento en el número de visitantes, y una contracción bruta de sus ingresos; en los últimos dos años parece retornar paulatinamente al crecimiento como es posible observar en el cuadro 2 .

Cuadro 2

Indicadores del turismo, 2000-2006

\begin{tabular}{lrrrrrrr}
\hline & 2000 & 2001 & 2002 & 2003 & 2004 & 2005 & 2006 \\
\hline $\begin{array}{l}\text { Turistas visitantes } \\
\text { (Miles) }\end{array}$ & 1774 & 1774.5 & 1686.2 & 1906 & 2049 & 2319 & 2221 \\
& & & & & & & \\
$\begin{array}{l}\text { Ingresos brutos del turismo } \\
\text { (Millones de pesos) }\end{array}$ & 1948.2 & 1840.4 & 1769.1 & 1999.2 & 2113.6 & 2398.9 & 2403.8 \\
\hline
\end{tabular}

Fuentes: Oficina Nacional de Estadísticas (ONE), Anuario Estadístico de Cuba 2006, La Habana, 2007. , Panorama Económico y Social de Cuba 2006, La Habana, 2007.

Esta situación de deterioro en el sector turístico puede atribuirse a la caída en la inversión extranjera por restricciones estatales, al aumento de la tasa de inflación que lo hace menos competitivo frente a otros destinos turísticos de la misma zona geográfica, a los deficientes servicios de transporte que ofrece Cuba, y a factores externos como la prohibición impuesta por Estados Unidos a sus habitantes de viajar a la isla.

\section{Situación actual}

Cuba superó el "periodo especial" de 1990-2003, resistió a la crisis económica a pesar del enorme deterioro causado en las condiciones de vida de su población gracias al remozamiento de su marco fiscal, comercial y financiero, al relanzamiento de los servicios turísticos, al aumento en los precios internacionales del níquel que elevaron el monto de sus exportaciones, a la comercialización externa de medicamentos y servicios médicos, a la tendencia creciente de flujos de inversión extranjera directa, al envío de remesas de familiares residentes en el extranjero y, sobre todo, a que se mantuvo elevado el volumen de inversión en educación (15\% en promedio en la década reciente), y en salud pública y asistencia social ( $8 \%$ en los últimos siete años) pudo lograr una eficaz utilización de sus fuerzas internas: su avanzado sistema de servicios sociales, las capacidades útiles de su población, la paz social y política, la actitud reactiva del Estado para combinar en la actividad económica eficiencia y ejercicio de controles severos con objeto de impulsar la producción industrial y su 
diversificación. No obstante, el bajo porcentaje de la formación bruta de capital fijo respecto al PIB en años recientes - 12.9\% en 2000 y 8.9\% en 2003 (ONE, Panorama Económico y Social de Cuba 2006:IV.5) — demuestra no haber logrado por ahora ese objetivo, y que en este sentido Cuba se inscribió dentro de la misma tendencia de los países latinoamericanos de mayor desarrollo relativo.

\section{Producción azucarera}

La producción de azúcar, pivote de la economía cubana durante los siglos, sufrió graves dificultades en la década de los noventa del siglo XX y los primeros años del siglo XXI, y se resumió en un severo desplome concretado en 2006, al disminuir a un tercio de los 3.6 millones de toneladas producidas en 2001, y sólo pudo lograr una participación de $12.4 \%$ de las exportaciones de mercancías, lo que reflejó un deterioro en la capacidad de generar ingresos en divisas. Esta tendencia se puede observar en el cuadro 3.

Cuadro 3

Indicadores de la producción azucarera, 2000-2006

\begin{tabular}{lccccccc}
\hline & 2000 & 2001 & 2002 & 2003 & 2004 & 2005 & 2006 \\
\hline $\begin{array}{l}\text { Azucarera } \\
\text { (Millones de toneladas) }\end{array}$ & 3.9 & 3.6 & 3.3 & 2.1 & 2.5 & 1.3 & 1.1 \\
$\begin{array}{l}\text { Rendimiento industrial } \\
\text { (Porcentajes) }\end{array}$ & 10.9 & 10.7 & 10.1 & 9.6 & 10.3 & 10.6 & 10.3 \\
$\begin{array}{l}\text { Ingresos por exportaciones } \\
\text { (Millones de pesos) }\end{array}$ & 453 & 550 & 448 & 289 & 272 & 149 & 219 \\
\hline
\end{tabular}

Fuentes: ONE, Anuario Estadístico de Cuba 2006, La Habana, 2007.

Habana, 2006.

El desmoronamiento de la producción azucarera en Cuba y su menor presencia en el mercado exterior son ocasionados por la pérdida de competitividad ante las exportaciones de países como Brasil, Australia, Guatemala y Tailandia (Nova, Armando, 2004). Esta situación condujo a una reestructuración de la rama azucarera consistente en ser sustituido el cultivo de caña de azúcar y en el cierre de la mitad de las centrales azucareras.

Otros bienes tradicionales que también han visto caer su participación en el PIB cubano son el tabaco, mercancía tradicional de venta al exterior que apenas logró $10 \%$ del volumen de las exportaciones en 2004, debido a su falsificación en algunos mercados. 
Producción de níquel

La producción comercial de níquel — realizada con nueva tecnología proporcionada por la asociación de capital extranjero (canadiense y chino) y nacional, y favorecida por una mejoría en los precios mundiales- multiplicó su importancia en las ventas al exterior al alcanzar el primer lugar de las exportaciones de mercancías en 2006 con $50 \%$ del total, lo que permitió reemplazar de esta manera la producción azucarera, y colocarse en una posición importante dentro de la estructura económica de Cuba.

La producción de sínter, combinación de óxido y sulfuro de níquel más cobalto, ha mantenido una tendencia creciente desde los años noventa hasta la actualidad como se muestra en el cuadro 4. Las cifras de la producción y exportación para 2005 y 2006 son demasiado imprecisas (se cree que ya sobrepasó las 100 mil toneladas) y la oficina nacional de estadística no ha publicado los datos oficiales.

Cuadro 4 Indicadores de la producción de níquel

\begin{tabular}{ccc}
\hline Año & $\begin{array}{c}\text { Producción de níquel }+ \text { cobalto } \\
\text { (Miles de toneladas) }\end{array}$ & $\begin{array}{c}\text { Exportaciones de níquel }+ \text { cobalto } \\
\text { (Millones de pesos) }\end{array}$ \\
\hline 1991 & 33.9 & 230.6 \\
1992 & 32.4 & 226.2 \\
1993 & 30.2 & 142.4 \\
1994 & 26.9 & 196.0 \\
1995 & 42.7 & 323.7 \\
1996 & 53.7 & 395.1 \\
1997 & 61.5 & 415.4 \\
1998 & 67.7 & 341.7 \\
1999 & 66.5 & 394.1 \\
2000 & 71.4 & 573.3 \\
2001 & 76.5 & 437.9 \\
2002 & 75.2 & $\mathrm{n} . \mathrm{d}$. \\
2003 & 70.9 & $\mathrm{n} . \mathrm{d}$. \\
2004 & 75.9 & $\mathrm{n} . \mathrm{d}$. \\
\hline Fuentes: ONE, Anuarios Estadísticos de Cuba 1997 y 2001, La Habana, 1998 y 2002. \\
\hline Cuba en Cifras Indicadores Económicos, Sociales y Demográficos del País 2005, La Habana,
\end{tabular}

Esta exitosa rama de producción no ha desarrollado encadenamientos productivos debido a que en Cuba se produce el mineral en bruto, y la empresa canadiense Sherritt Internacional Ltd, con fuertes inversiones en la isla, se encarga de transportarlo a Canadá, donde es refinado.

La reconversión económica de Cuba ha ocasionado la nueva incorporación al rubro de las exportaciones de productos como los servicios médicos y las medicinas que contribuyeron con $6 \%$ del total en 2005. Además, el sector energético controlado 
por el Estado — como extracción de petróleo, gas y generación de energía eléctricaha experimentado fuertes cambios desde los años noventa. En el "periodo especial" estableció empresas mixtas con capital extranjero y cuadruplicó su producción de 0.8 toneladas en 1991 a 3.3 en 2000. En la actualidad la asociación de los gobiernos de Cuba y Venezuela, sin abandonar la vía tradicional de extracción de crudo, pretende avanzar en la producción de biocombustibles a partir de la extracción de alcohol de la caña de azúcar, y generar energía eléctrica con biomasa cañera (IPS, 2006: 3-5).

Ante la recomposición de las relaciones comerciales de Cuba, y su estrecha vinculación con China y Venezuela, el gobierno estadounidense recrudeció el embargo, impuso restricciones al turismo, a las remesas de familiares, y ha dificultado la venta de alimentos estadounidenses a la isla, ya que en 2001 le vendieron mil 177 millones de dólares de productos agrícolas y en 2005 la cifra sólo llegó a 350 millones de dólares. Esta medida profundizó el déficit comercial crónico de Cuba (cinco mil 529.4 millones de pesos cubanos, $12 \%$ del PIB en 2005), el cual no afectó al superávit de la balanza de pagos superior a los 160 millones de dólares en 2005 como consecuencia de la venta de servicios sanitarios a Venezuela, la compra de petróleo de ese país a precio preferencial y a crédito, y las facilidades crediticias otorgadas por los exportadores chinos que han compensado los problemas financieros de la nación caribeña, y las limitaciones de su modelo de desarrollo dependiente del exterior sin ser una economía abierta. Esta "mejor situación económica de Cuba", mostrada en el comportamiento de los principales indicadores, le ha permitido al Estado —en 2005-2006 - optar por una economía más controlada y centralizada, regida por su acción empresarial y social abandonando la orientación reformista y descentralizadora de los años noventa.

Si Cuba no afronta las restricciones financieras, la fuerte burocratización y el embargo estadounidense, tendría un camino más cercano a una apertura comercial y económica, pues su protección media ante los miembros de la Organización Mundial de Comercio (OMC, organismo del cual forma parte) es de $10 \%$ con variantes de $35 \%$ en productos seleccionados, y para algunos países (sobre todo Venezuela) e importadores (entre ellos el propio Estado) los aranceles afectan poco, las licencias son el verdadero canal limitante.

\section{Resultado de las decisiones de política económica}

De acuerdo con la información proporcionada por la Oficina Nacional de Estadísticas y los Ministerios de Asuntos Económicos de Cuba — véase la gráfica 2 - la economía de este país registra un crecimiento del PIB comparativo con el de China 
en los últimos dos años $(2005,11.8 \%$, y 2006, $12.5 \%)$ por el notable incremento en la generación de servicios de salud y educación, medicamentos y níquel que se comercializan en el mercado exterior, y el apoyo económico de Venezuela y China, que han compensado la restricción de envío de remesas desde Estados Unidos, los daños ocasionados por los huracanes, la sequía y la insuficiente generación de energía eléc-

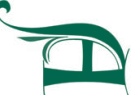
trica. Es de suma importancia señalar que en Cuba han sido modificados los cálculos estadísticos de los indicadores económicos, y se desconoce la nueva metodología. Por esta razón las cifras correspondientes al PIB de 2005 y 2006 pueden ser imprecisas.

Gráfica 2

Producto Interno Bruto (Tasas anuales de variación)

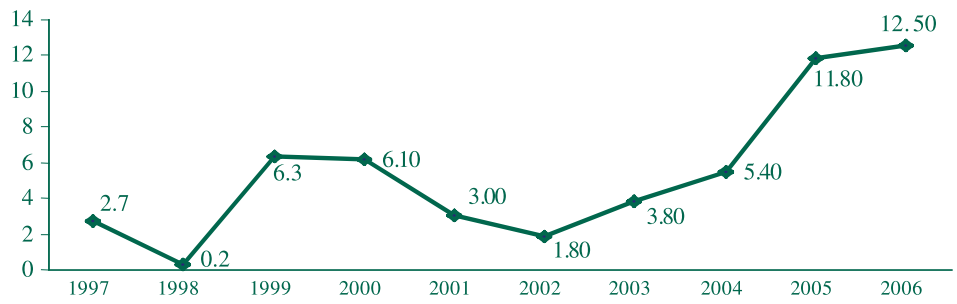

Fuente: ONE, Anuario Estadístico, 2005, La Habana, 2006.

A la par del mayor crecimiento económico ha aumentado la brecha fiscal a 4.9\% del PIB en 2006 como resultado de un mínimo incremento de los ingresos tributarios del Estado, una caída de los ingresos no tributarios y un aumento en el gasto social, como se puede apreciar en la gráfica 3. La mayor recaudación de impuestos indirectos, de circulación y sobre ventas, y gravámenes directos sobre utilidades, utilización de la fuerza de trabajo y contribución a la seguridad social no equilibraron la disminución de los impuestos sobre ingresos personales por mayor restricciones al trabajo por cuenta propia, y el aumento en el gasto público (mayores pensiones y salarios) dirigido a corregir los problemas de gestión y desigualdades sociales aparecidos en el "periodo especial", y que minaban la cohesión política y social. En esta orientación, el Estado, con el fin de elevar el nivel de vida de la población y reducir la tasa de desempleo a $1.9 \%$, ha operado como empleador de última instancia desde 2005, elevando el número de trabajadores estatales, e incrementado las pensiones, las ayudas de asistencia social, las remuneraciones en especie, las ventajas sociales, y fijando el salario monetario en un rango de 14-17 dólares mensuales (336-408 pesos cubanos no convertibles). Con objeto de cumplir el objetivo de resarcir a la población del deterioro sufrido en el periodo de crisis, se inició en 2005-2006 un plan bianual 
de construcción de vivienda que cristalizó en más de 39 mil nuevas casas en el primer año, duplicándose la producción anual de 2004 (Ministerio de Finanzas y Precios, 2004:1-11).

Gráfica 3

Déficit presupuestal (Porcentaje del PIB)

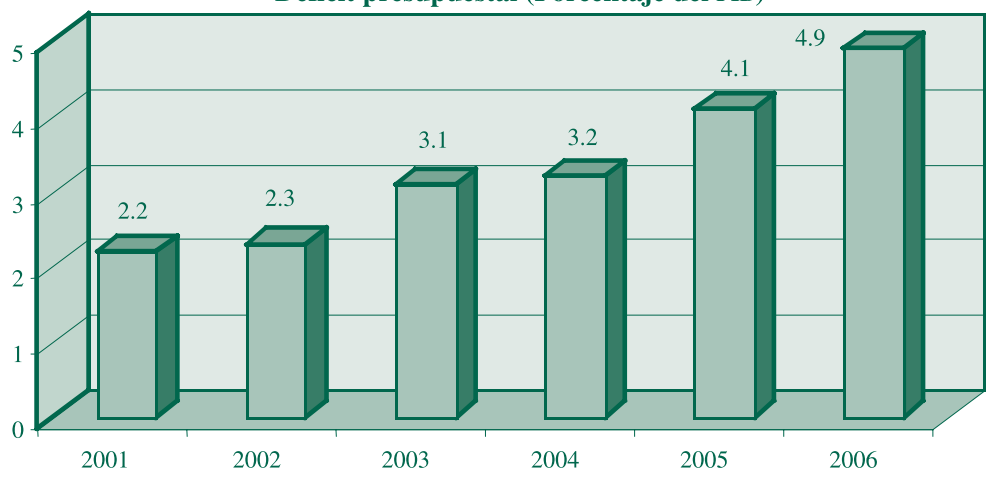

Fuente: ONE, Anuario Estadístico, 2005, La Habana, 2006.

La política monetaria de los últimos años (2003-2006) se ha concentrado en desdolarizar a Cuba. Se suprimió la circulación de billetes de dólar, se decretó que las empresas cubanas cedan sus ingresos en divisas al Banco Central de Cuba, institución que inició la aplicación de una mayor disciplina financiera por medio de su Comité de Autorización de Divisas, encargado de autorizar los gastos en divisas y las contrataciones internacionales que impliquen tales gastos. En marzo de 2005 se dio una revaluación de $7 \%$ del peso cubano no convertible frente al peso cubano convertible, acción que llevó al tipo de cambio comercial a 24 pesos cubanos por dólar, y a que el tipo de cambio oficial se revaluara en $8 \%$ contra las demás divisas al colocarse en 1.08 dólares por peso cubano convertible (CUC). En tanto, las tasas de interés para personas jurídicas y naturales han permanecido sin cambios desde 2004, y son las que aparecen en los cuadros 5 y 6 .

Cuadro 5

Tasas de Interés Anual 2004-2006

Personas Jurídicas

Plazos (meses)

\begin{tabular}{lccccccc}
\hline Moneda & A la vista & 1 & 2 & 6 & 12 & 24 & 36 \\
\hline CUC & 1.75 & 2.25 & 2.25 & 2.25 & 2.50 & 2.75 & 3.25 \\
USD & 1.75 & 2.00 & 2.10 & 2.15 & 2.5 & 2.75 & 3.25 \\
\hline
\end{tabular}

Fuentes: Banco Central de Cuba (BCC), Política Monetaria, 2007.

CUC (Peso Cubano Convertible)

USD (Dólar Estadounidense) 


Cuadro 6
Tasas de Interés Anual 2004-2006
Personas Naturales
Plazos (meses)

Fuentes: Banco Central de Cuba (BCC), Política Monetaria, 2007.

CUC (Peso Cubano Convertible)

USD (Dólar Estadounidense)

CUP (Peso Cubano No Convertible)

Los incrementos de salarios y pensiones sumados al aumento en las cotizaciones de diversos bienes y servicios en el mercado formal (huevo, arroz, café, electricidad y tarifas de transporte) han contribuido al crecimiento de las ventas minoristas y de la circulación monetaria colocando la tasa de inflación a 5.5\% en 2006 (CEPAL, 2006:205), pero en una economía con precios intervenidos y dos segmentos de mercado claramente diferenciados - uno en pesos cubanos no convertibles y cada vez menos relevante, y otro en dólares o pesos cubanos convertibles- el incremento de precios puede ser mayor. La secuencia porcentual de la inflación para 1997-2007 es posible observarla en la gráfica 4.

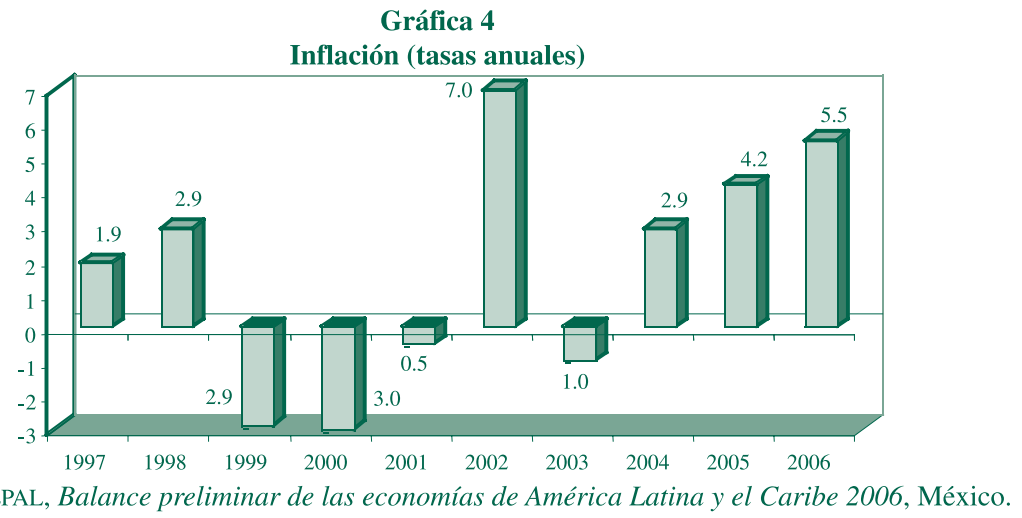

A finales de 2005 el gobierno cubano llevó a cabo importantes reformas económicas y sociales con el objetivo prioritario de reducir al máximo las desigualdades sociales y económicas aparecidas durante el "periodo especial". Emprendió el combate a la corrupción, incrementó los precios de los productos subsidiados como la electricidad, y elevó el nivel de ingreso de los trabajadores en función del trabajo efectivamente aportado para elevar la productividad. 
La pretensión oficial de estas medidas monetarias y sociales es disminuir la diferencia de poder adquisitivo entre la población que recibe ingresos en divisas y la que cobra en moneda nacional, y probablemente el fin último sea doble: a) contar con una moneda única y b) evitar la propagación de la ideología disidente.

Junto a las medidas monetarias, la deuda externa pública de Cuba de 12 mil millones de dólares (80\% vencida), que significó 45\% del PIB en 2004 y más de 230\% de las exportaciones de bienes y servicios, es una preocupación constante; tras la suspensión de pagos de 1986 el país está clasificado en el séptimo y último grupo, así que se pretende renegociarla en el Club de París (ONE, 2006:VII.2) en fecha no prevista, porque los principales acreedores de la deuda cubana — Japón, principal acreedor (17\%), seguido por Argentina (14.8\%), España (13.3\%) y Francia (9.9\%)— no muestran mucho interés al considerarla poco significativa. Además, está la deuda con la ex Unión Soviética y otros países ex socialistas, con un monto de 22 mil millones de rublos, pero Cuba no la reconoce. En general, la deuda externa correspondiente al periodo 2002-2006 es atendida de forma selectiva, se paga a los acreedores con vencimientos más sencillos y se realizan compras con pagos adelantados, como es el caso de la compra de alimentos provenientes de Estados Unidos.

Las reformas legales emprendidas en 1997, con objeto de permitir y fomentar la conformación de un sistema del sector bancario y financiero - capaz de proporcionar financiamiento a los sectores productivos, a las exportaciones e importaciones, ofrecer operaciones de arrendamiento financiero, factoraje, descuento de efectos comerciales (letras de cambio cuyo uso es muy extendido) y coberturas de tasas de interés y riesgo cambiario_- han conducido a que en 2006 éste haya quedado integrado como se puede apreciar en el cuadro 7: un banco central, nueve bancos comerciales (tres son empresas de inversión mixta); 18 instituciones financieras no bancarias (al menos cinco de ellas son de propiedad mixta); 13 oficinas de representación de bancos extranjeros, y cuatro oficinas de representación de instituciones financieras no bancarias.

Un aspecto importante en todo análisis económico de un país en transición es conocer el financiamiento que su sistema financiero proporciona a los sectores productivos y sociales. En el caso de Cuba fue posible conocerlo de forma agregada para 1997 y 1998 en un estudio de la CEPAL, en el que reporta un total de 779.1 millones de dólares para el primer año y mil 5.8 millones para el segundo año en cuestión, montos distribuidos de la siguiente manera: sector industrial beneficiario de $49.7 \%$ y $54 \%$ para esos años, seguido por el comercio con $36.7 \%$ y $21.3 \%$ respectivamente, y muy por debajo de ellos al sector agrícola con una participación de 3.9\% en 1997 y 4.9\% en 1998 (CEPAL, 2000: Apéndice Estadístico). 
Cuadro 7

Composición del sistema bancario y financiero de Cuba, 2006

Instituciones bancarias y financieras Instituciones financieras no bancarias

- Banco Central de Cuba (BCC)

- Grupo Nueva Banca S.A (NB)

- Financiera Nacional S.A. (FINSA)

- Casa de Cambio S.A. (CADECA)

Bancos Comerciales

- Compañía Fiduciaria S.A. (CFSA)

- Rafin S.A. (RSA)

- Banco Nacional de Cuba (BNC)

- Banco de Crédito y Comercio (BANDEC)

- Casa Financiera de

- Banco Popular de Ahorr (BPA)

- Banco Exterior de Cuba (BEC)

- Fimel S.A. (FSA)

- Banco Financiero Internacional (BFI)

- Corporación Financiera Azucarera S.A. (ARCAZ)

- Finagri S.A.

- Banco Internacional de Comercio S.A. (BICSA)

- Corporación Financiera Habana S.A. (CFH)

- Banco Metropolitano S.A.

- Financiera CIMEX S.A

- Banco de Inversiones S.A. (BISA)

- Banco Industrial Venezuela Cuba S.A

- Financiera para el Turismo S.A. (FINATUR)

- Financiera para la Industria Alimenticia S.A. (ALFI)

- Interholdings S.A.

- Financiera Iberoamericana S.A.

- Financiera del Transporte (TRANSFIN)

- Empresa de Información Crediticia y Financiera S.A.

(INCREFIN)

- Compañía Financiera S.A.

Oficinas de Representación de Bancos Extranjeros

- Havana International Bank Ltd.

Oficinas de Repres. Instit. Financ. No Bancarias

- ING Bank N.V.

- Netherland Caribbean Bank

- National Bank of Canada

- Caribbean Finance Investments Ltd. (Carifin)

- CDC Capital Partners

- Fincomex Ltd.

- Novafin Financiere S.A

- Banco Bilbao Vizcaya Argentaria S.A.

- Banco Sabadell S.A.

- Société Générale

- Fransabank Sal

- Banco Nacional de Comercio Exterior SNC (Bancomext)

- Caja de Ahorros y Monte de Piedad Madrid (Caja

Madrid)

- BNP Paribas

- EBN Probanza

- Republic Bank Ltd.

Fuente: Elaboración propia

Datos tomados de Solorza, Marcia, "Sistema Financiero en una economía en transición: los Bancos en Cuba", en Revista Ola Financiera, México, IIEC-UNAM, 2005.

Reportes del Banco Central de Cuba permitieron recabar algunos datos referidos al financiamiento otorgado por bancos comerciales, financieras extranjeras e instituciones financieras no bancarias en 2001. El Banco Popular de Ahorro (BPA), institución bancaria comercial que concentra $40 \%$ de las cuentas bancarias de la población cubana, otorgó financiamiento individual a compañías nacionales por 72 mil 450 millones de dólares (15 mil 750 millones de dólares a personas y 56 mil 700 millones de dólares a empresas); Caribbean Finance Investments (CARIFIN), institución financiera extranjera, respaldó con 60 millones de dólares a todos los sectores económicos (comunicaciones $21.1 \%$, transporte $15 \%$, sideromecánica $13 \%$, turismo $6.8 \%$, electrónica $6.6 \%$, industria básica $6 \%$, financiero $5.1 \%$, industria ligera $4.5 \%$, pecuario $4.1 \%$, tiendas $4.1 \%$, y otros $12.4 \%$ ). Las instituciones financieras no bancarias de inversión mixta (extranjera y nacional) a mediano y largo plazos a procesos productivos 
y comerciales registraron lo siguiente: FIMEL, SA, garantizó financiamientos por 18.4 millones de dólares y obtuvo créditos extranjeros para entidades nacionales por 97.3 millones de dólares (en total canalizó financiamiento por 115.7 millones de dólares); FINAGRI, SA, prestó entre 1998 y 2001 el monto de 367 millones de dólares (312 millones para respaldar al sector agropecuario y 55 millones de dólares a otros); Corporación Financiera Habana, SA (CFH) de 1998 a 2001 invirtió 33 millones 121 mil 363 dólares en créditos; FINATUR, SA, en el periodo 1992-2001, mediante financiamientos por 780 mil 600 millones de dólares, respaldó a la actividad productiva (industria textil, alimentaria, bebidas, confecciones, plásticos, muebles, vidrio, papel), a la agricultura, el turismo y a tiendas de recaudación de divisas; ALFI, SA, en 2001 operó préstamos por 92 millones de dólares, y Financiera del Transporte (TRANSFIN) en 2000 financió al sector de transportes con 99 mil 900 millones de dólares (62 mil 300 millones de dólares a suministradoras o consumidoras de bienes y equipo).

\section{Conclusiones}

Indudablemente Cuba tiene una economía en lenta transición y con grandes ambigüedades en su rumbo. El Estado cubano conserva su fortaleza y su posición económica intervencionista, fomenta la simbiosis de mecanismos de mercado con medidas de planificación centralizada, en donde la inversión extranjera directa y las instituciones bancarias tienen un papel fundamental en el impulso al crecimiento económico.

Las reformas fiscal, de inversión, monetaria y financiera de los años noventa e inicios del siglo XXI trastocaron la modalidad de desarrollo económico puesto en marcha por el Estado cubano a lo largo de tres décadas (1959-1989), con lo que logró resultados importantes en el crecimiento y la estabilidad económica, a pesar del recrudecimiento del embargo estadounidense y cuyos daños se estiman para 2006 en aproximadamente 270 mil millones de dólares.

La economía cubana es muy vulnerable en sus relaciones económicas internacionales por los intercambios desiguales y el escaso control que tiene sobre las condiciones mercantiles y financieras en que se realizan, expresadas en el crónico desequilibrio de su balanza comercial, el nivel de endeudamiento y el alza de precios.

Las medidas de política económicas adoptadas en los últimos 20 años han contribuido a transformar la situación y perspectivas industriales de la economía cubana sin trastocar sustancialmente el modelo primario-exportador de los siglos XIX y XX y la percepción de quienes dirigen las fuentes de financiamiento internacional.

Los problemas estructurales de la economía cubana - mostrados en el cuerpo del trabajo- , la actitud ambigua del Estado que restringe el desarrollo del mercado in- 
terno y que a la vez busca y necesita ampliar la presencia de los bienes producidos en Cuba en el mercado internacional como vía de subsanar las crisis económicas, sumados a la participación activa de actores externos como Estados Unidos y los propios colectivos de cubanos fuera de su país, han conducido a Cuba y a sus pobladores a un punto que exige reflexionar acerca de las opciones político-económicas para lograr

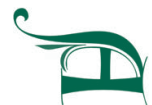
cambios estratégicos en un futuro no lejano.

El Estado podría jugar un papel importante en la transformación de la economía en Cuba si es artífice de nuevas políticas industriales, comerciales, financieras, fiscales, de salud, educación y seguridad social que promuevan el desarrollo al dinamizar su mercado interno, si estimula la inversión extranjera directa, los negocios, y renueva y moderniza el parque industrial con los recursos naturales y humanos del país.

\section{Bibliografía}

Aoki, Masahiko, "An Evolving Diversity of organizational Mode and its Implications for Transitional Economies", en Journal of the Japanese and International Economies, vol. 9, núm. 4, San Diego, Academic Press, diciembre de 1995, pp. 330-353.

Banco Central de Cuba, Informe Anual, La Habana, Banco Central de Cuba, febrero de 1998-2006.

, El sistema bancario y financiero de Cuba, La Habana, Banco Central de Cuba, 1998.

Coase, Ronald, "The Problem of Social Cost", en Journal of Law and Economics, núm. 3, Chicago, University of Chicago, octubre de 1960, pp. 1-44.

"The Institutional Structure of Production”, en Claude, Ménard y Mary M. Shirley (eds.) Handbook of New Institutional Economics, Netherlands, Springer, 2005, pp. 31-41.

Centro de Estudios de la Economía Cubana, Balance de la economía cubana a finales de los 90's, La Habana, Universidad de La Habana, 1999.

CEPAL, La economía cubana, reformas estructurales y desempeño en los noventa, México, FCE, 2000.

, Balance preliminar de las economías de América Latina y el Caribe, México, CEPAL, 2006.

Deere, Carmen, "Reforming Cuban Agriculture", en Journal Development and Change, vol. 28, núm.4, La Haya, Institute of Social Studies-Blackwell Publishing, octubre de 1997, pp. 649-669.
Estévez, Manuel, "La Inversión Extranjera en la República de Cuba en la Etapa Contemporánea", en Revista Galega de Economía, vol. 9, núm. 2, Santiago de Compostela, FCEE-USC, diciembre de 2000.

García, Jesús, La reforma monetaria en Cuba, México, CEPAL, 2005.

García, Mercedes, "Cuba, Desempeño Económico en el Periodo 1995-2000. Principales Logros Alcanzados", en Revista del Banco Central de Cuba, núm. 2, La Habana, Banco Central de Cuba, abril-junio de 2001.

Gimeno, Juan Luis y Roberto López Salvador, Cuba, medios de pago, Madrid, Instituto Español de Comercio Exterior, 2004.

Inter Press Service, "Resumen Económico Anual Año de Interrogantes", en Revista Cuba a la Mano, núm.1, La Habana, Corresponsalía Inter Press Service América Latina, 2006.

Levins, Richard, "La lucha por una agricultura ecológica en Cuba", en Ecología Política, núm. 2, Barcelona, Icaria, 1990, pp. 83-96.

Martínez-Heredia, Fernando y John Saxe-Fernández, Geoeconomía y geopolítica en el Caribe, México, IIEC-UNAM, 1997.

, Desafíos del socialismo cubano, México, Meztiza/CEA, 1988.

, "La alternativa cubana", en John Saxe-Fernández (coord), Tercera vía y neoliberalismo, México, Siglo XXI-CIICHUNAM, 2004, pp. 102-128.

Ministerio de Finanzas y Precios, Presupuesto del Estado, La Habana, Ministerio de Finanzas y Precios, 2004. 
Nova, Armando, "Redimensionamiento de la agroindustria azucarera cubana. Historia y Actualidad", en Pérez Villanueva, Omar E. (ed.), Reflexiones sobre la economía cubana, La Habana, Ciencias Sociales, 2004.

Oficina Económica y Comercial de España en La Habana, Informe económico y comercial de Cuba, La Habana, Oficina Económica y Comercial de España en La Habana, marzo de 2006.

Oficina Nacional de Estadística, Anuario estadístico de Cuba 1997, La Habana, Oficina Nacional de Estadística, 1998.

, Anuario estadístico de Cuba 2001, La Habana, Oficina Nacional de Estadística, 2002.

Anuario estadístico de Cuba 2006, La Habana, Oficina Nacional de Estadística, 2007.

Cuba en cifras. Indicadores económicos, sociales y demográficos del país 2005, La Habana, Oficina Nacional de Estadística, 2006.

, Panorama económico y social de Cuba 2006, La Habana, Oficina Nacional de Estadística, 2007.

Pérez, Carlos, et al., "Aproximación al estudio de los mecanismos de transmisión de la política monetaria en Cuba", en Revista Economía y Desarrollo, año XXIII, vol. 134, edición especial, La Habana, Facultad de Economía-Universidad de La HabanaFundación Friedrich Ebert, diciembre de 2003, pp. 22-58.

Pérez-Villanueva, Omar, Las reformas económicas en Cuba en los 90's, Santiago de Compostela, Universidad de Santiago de Compostela, 1996.

"La inversión extranjera en Cuba. Peculiaridades", Xx Congreso Internacional Latin American Studies Association, Ponencia, Guadalajara, 1997.

"Estabilidad macroeconómica y financiamiento externo: la inversión extranjera directa en Cuba", XXII Congreso Internacional Latin American Studies Association, Ponencia, Miami, 2000.

Presidencia del Consejo de Estado de la República de Cuba, "Decreto-Ley Número 50 de la Inversión Extranjera", en Gaceta Oficial de la República de Cuba, Año LXXXI, Edición Extraordinaria núm. 16, La Habana, 15 de febrero de 1982, p. 127.

, "Decreto-Ley Número 73 del Sistema Tributario", en Gaceta Oficial de la
República de Cuba, Año XCII, Edición Extraordinaria núm.8, La Habana, 4 de agosto de 1994.

"Decreto-Ley Número 77 de la Inversión Extranjera", en Gaceta Oficial de la República de Cuba, Año XCIII, Edición Extraordinaria núm.3, La Habana, 5 de septiembre de 1995.

" "Decreto-Ley Número 165 de Zonas Francas y Parques Industriales", en Gaceta Oficial de la República de Cuba, año XCIV, Edición Extraordinaria, La Habana, 3 de junio de 1996.

"Decreto-Ley Número 172 del Banco Central de Cuba", en Gaceta de la República de Cuba, año XCV, Edición Extraordinaria núm. 4, La Habana, 28 de mayo de 1997.

"Decreto-Ley Número 173 Sobre los Bancos e Instituciones Financieras no Bancarias", La Habana, en Gaceta Oficial de la República de Cuba, año XCV, Edición Extraordinaria núm. 4, La Habana, 29 de mayo de 1997.

, "Decreto-Ley Número 192 de la Administración Financiera del Estado", en Gaceta Oficial de la República de Cuba, año XCVII, Edición Extraordinaria núm. 2, La Habana, 8 de abril de1999.

Sachs, Jeffrey y Wing Thye Woo, "Experiences in Transition to a Market Economy", en Journal of Comparative Economics, Massachusetts, Harvard University, vol. 18, núm. 3, junio de 1994, pp. 271-275.

Solorza, Marcia, "Sistema Financiero en una economía en transición: los bancos en Cuba", en revista electrónica Ola Financiera, México, IIEC-UNAM, 2005.

Stiglitz, Joseph, "Knowledge for Development Economic Science Economic Policy and Economic Advice", en Annual World Bank Conference on Development Economics 1998, Washington, DC, World Bank, abril de 1999, pp. 9-58.

Suchlicki, Jaime y Antonio, Jorge (eds.), Investing in Cuba, Problems and Prospects, New Brunswick, Transaction Publishers, 1994.

Togores, Viviana y Anicia García, "Consumo, mercados y dualidad monetaria en Cuba", en Revista Economía y Desarrollo, año XXXIII, vol.134, edición especial, La Habana, Facultad de Economía-Universidad de la Habana-Fundación Friedrich Ebert, diciembre de 2003, pp. 165-223. 